\title{
Fluorine F-18 6-Fluorodopamine
}

National Cancer Institute

\section{Source}

National Cancer Institute. Fluorine F-18 6-Fluorodopamine. NCI Thesaurus. Code C91706.

A radioconjug ate consisting of 6-fluorodopamine labeled with fluorine F18 (6-[18F]FDA), with potential diagnostic activity. Upon administration, 6-[18F]FDA is taken up by presynaptic sympathetic nerve endings via the norepinephrine transporter (NET) uptake1. Once inside, 6-[18F]FDA is rapidly converted by dopamine-beta-hydroxylase into 6[18F]fluoronorepinephrine (6-[18F]FNE) and stored into neuronal storage vesicles. Upon positron emission tomographic (PET) scanning of the F18, sympathetic innervated regions can be visualized, such as those in pheochromocytoma. 